\title{
Developmental Psychopathology Approach in Addiction Diagnosis in Adolescence
}

\author{
Marzanna Farnicka', Miguel Bettin ${ }^{2}$ \\ ${ }^{1}$ University of Zielona Góra, Zielona Góra, Poland \\ ${ }^{2}$ Científico del Instituto de Estudios Psicobiosociales y de Intervención en Violencias, Bogotá, Columbia \\ Email: farniccy@gmail.com
}

How to cite this paper: Farnicka, M., \& Bettin, M. (2019). Developmental Psychopathology Approach in Addiction Diagnosis in Adolescence. Psychology, 10, 710-721. https://doi.org/10.4236/psych.2019.105046

Received: March 15, 2019

Accepted: April 16, 2019

Published: April 19, 2019

Copyright (c) 2019 by author(s) and Scientific Research Publishing Inc. This work is licensed under the Creative Commons Attribution International License (CC BY 4.0).

http://creativecommons.org/licenses/by/4.0/

\begin{abstract}
In order to provide multilevel potential explanations for the co-occurrence of addiction disorders and their developmental complex influence, developmental psychopathology has been considered to be an integrative perspective in research and in clinical treatment. This paper examined developmental psychopathology approach in addiction diagnosis and treatment. There is an historical and informative perspective that discusses two issues. The former is connected with the antecedents of addiction diagnosis. The latter parts of the article refer to the principles of developmental psychopathology and studies carried out in this field. In conclusion, the value of this perspective in diagnostic decision-making processes in adolescents is also discussed.
\end{abstract}

\section{Keywords}

Addiction, Context, Youth Development, Diagnosis

\section{What Is the Problem?}

Looking at the practice, the presence of diagnosis problems in adolescence is more a "rule" than an exception. And many disorders occurring in the developmental period between childhood and the end of adolescence have "developmental" or "situational" characteristics (Beauchaine, 2003; Krueger \& Markon, 2011). It is important to take into account the contexts of young people's development, the specificity of their activity and their level of development. During adolescence, children experience many cumulative stress situations related to puberty, education and social needs. Parental influence is diminished, with a significant increase in the role of the peer group. The weakening of parental ties results in increased vulnerability to peer pressure, which can lead to many problems. Peer pressure can mediate in the development of pathological behaviours, 
including the use of psychoactive substances and other addictive behaviours (Grzegorzewska, 2013). During this developmental period, increased neuronal sensitivity to the so-called rewarding behavior leading to addiction has been documented (Tapert, Caldwell, \& Burke, 2005). The rewarding function is also performed by various addictive behaviors, including playing video games or eating. There is also increased vulnerability among young people to the development of addictive mechanisms. However, in many cases, criteria and tools used for adults are not always appropriate for diagnosing adolescents or children. This implies the need to prepare versions of scales for the diagnosis of behavioral addictions in adolescents, as many diagnostic methods prepared for adults cease to be accurate and reliable for young people. In addition, researchers found that parallel treatments were ineffective, suggesting a need to integrate the services addressing mental health with those addressing substance abuse (Chassin, Sher, Hussong, \& Curran, 2013).

\section{Developmental Trajectories of Addiction Problems in Adolescence}

Research findings have shown that the first symptoms that indicate the possibility of developing addictions appear during adolescence or earlier (Hawkins \& Fitzgibbon, 1993), and the full diagnosis of substance addiction appears in early adulthood, and increasingly often also during adolescence (Chassin, Sher, Hussong, \& Curran, 2013). The literature on substance addition indicates that early exposure to psychoactive substances (e.g. alcohol, nicotine) increases the risk of developing substance addictions during adulthood. It is believed that this risk is associated with increased biological vulnerability and greater life stress. Studies conducted by Compas, Heiden and Gerhardt (1995) on trajectories of development pathways in adolescents clearly show their heterogeneity. The stability and variability of development in relation to addictive behaviour are confirmed by a two-year study conducted by Gentile, Choo, Liau and Khoo (2011). An important observation resulting from the study is that the pathological playing of video games during childhood and adolescence cannot be treated as a transient problem. During the 2-year study of more than 3000 children aged $10-11$ and 14 15 years, $84 \%$ of the pathological players revealed in the first study still played addictively after two years. Also, in the same 2 -year period, only $1 \%$ of players became addicted to playing. This means that the pathological playing of video games cannot be considered as a "phase" or "stage" in the development of a child that passes with time.

So, the early symptoms of behavioural addictions that appear in childhood are important predictors of serious problems in the future.

\section{Developmental Function of Addiction}

Behaviours such as playing computer games, gambling, sports, eating or shopping serve many purposes: entertainment, relaxation, experiencing a sense of 
competence and independence, or escape from everyday problems (Griffiths, 2003; Ryan, Rigby, \& Przybylski, 2006). These behaviours (such as the use of video games) in children and adolescents can lead to a state of trance where the sense of time and place disappears, and there is a sense of control, power, and extreme inner satisfaction (Gentile et al., 2009). Such behaviours are not initially threatening, but may become pathological if they lead to negative consequences in everyday life. The central function in this process is played by the reward mechanism, or the subjective sense of pleasure. There is pleasure and satisfaction at the beginning of each addiction. A reward is intended to motivate and encourage adaptation. Mechanisms, structures and transmitters responsible for the development of addiction are constantly being studied: documented biological mechanisms of addictive behaviour are connected with the role of neurotransmitters (dopamine) and the cerebral reward system (mainly the mesolimbic pathway, Haass-Koffler \& Barlett, 2012; Hu, Fang, Yang et al., 2018; Tomkins \& Sellers, 2001).

The compulsive engagement of young people in various forms of pathological behaviour can fulfill many important functions in their development. In general, the two most important are satisfying the need for stimulation and coping with stress $^{1}$ (Grzegorzewska \& Cierpiałkowska, 2017). The need for stimulation is related to the temperamental characteristics of the individual, which for a long time have been identified as important personal correlates of behavioural habits (Cierpiałkowska, 2010). Although this is primarily related to substance abuse, more and more studies confirm their importance also in relation to behavioural addictions (Petry, 2015), including in children and adolescents (Conrod et al., 2013; Moffitt et al., 2011). In the literature, it is also emphasised that addictive behaviours can be a form of compensation for intrapersonal deficits such as low self-esteem or identity problems (Niemz, Griffiths, \& Baynard, 2005; Israelashvili, Kim, \& Bukobza, 2012). The Internet, and especially social media, give users an opportunity to create their own identity, which is not possible in the real world. Another function of addictive behaviours is to build relationships with others. For example, thanks to active participation in social media, young people can satisfy their needs for belonging and acceptance. The problem, however, is that social media increasingly replace real face-to-face contacts with other people (Davies \& Cranston, 2008) and actually create the illusion of belonging to a social group and having interpersonal relations (Grzegorzewska \& Cierpiałkowska, 2017).

The dynamics of developmental changes in childhood and adolescence may cause many diagnostic problems. Key determinants for the development of mental health disorders are recognized to comprise processes arising from interactions of previous factors in interpersonal relationships or in relation to social ${ }^{1}$ Gentile's (2011) study shows that children who started playing pathologically during the study were more likely to have depression, anxiety, and social anxiety, and children who stopped playing during the study had lower levels of depression, anxiety and social phobia. This means that intense gaming intensifies mental health problems in young people and contributes to the development of disorders. 
tasks and challenges such as fear of rejection or instability of family relationships. In the case of young people more than adults, the quality of their family and peer environment plays a significant role. The behavioral addiction development begins with environmental factors that include easy access to and social acceptance of such behaviours (Bubier, Drabick, \& Breiner, 2009). For example, in the case of pathological gambling, or using alcohol, marijuana, tobacco and other substances, it involves playing for money at home and with peers, using substances with friends and with their approval (or even parents' approval) (Blaszczynski \& Nower 2002). This shows that some problems could be only "situational" or adaptative.

\section{Solution: Developmental Psychopathology as an Integrative Perspective to Cope with Dual Diagnosis Problems}

Below some useful findings related to dual diagnosis treatment seen from the perspective of developmental psychopathology.

The developmental psychopathology principle suggests that developmental rules are universal for all. The differences are noticed in relation to bio- psychosocial characteristics of individuals and stressors. The analysis of determinants for the risk of addictions should take into account many related and complementary elements. The pathways that healthy or disturbed development follows depend on the interaction of risk and protective factors throughout the entire life of an individual, as well as the dynamic processes of requirement balancing (including life stresses, developmental tasks and social expectations) at a specific stage of development and in a specific life context. Therefore, in order to analyse individual addictions carefully, it is necessary to specifically address both risk factors (understood as the factors responsible for susceptibility to addiction and the factors that directly initiate and sustain addictive behaviours) and protective factors (understood as individual resilience, coping factors and personal potentials (Cicchetti, 1993; 2013).

It is assumed that it is not possible to gain a complete understanding of the development of addiction and mental disorders without analyzing the pathways leading to it. These pathways are usually complex, and their various causes and determining factors can lead to the same results (equifinality), or similar initial conditions result in varied developmental effects (equipotentiality) (Rutter, Dunn, Plomin, Simonoff et al., 1997; Cierpiałkowska \& Grzegorzewska, 2016). This means that for example not all addicted people are the same (they constitute a heterogeneous group), and each pathway differs in terms of the presence or absence of psychosocial and biological vulnerability factors such as: family, school, peers, undertaking developmental tasks and personality characteristics). The developmental paths are linear but also characterised by flexibility, intermittency and change. Stable paths are associated with adolescents growing up in a low-risk environment (adaptive path, Path 1) or adolescents experiencing dif- 
ficulty from early childhood and excessive chronic stress or trauma (non-adaptive path, Path 2). Paths that vary over time are associated with people in whom non-adaptation is limited only to the period of adolescence or those who function much better in adolescence than in childhood (Path 3 or 6), or those in whom adolescence means a permanent worsening in the level of functioning (Path 4 or 5). The variability and instability of developmental paths for children and adolescents can result from positive (e.g. new peers) or negative changes in a young person's environment (e.g. transition to middle school, parental divorce, death of a loved one) and biological and developmental changes (e.g. developmentally determined vulnerability to risky behaviour, new cognitive abilities, more independence) or hereditary factors appearing only in adolescence (Compas et al., 1995). It is worth that new paths could be stable (Path 3 and 4) and could give a new developmental environment or only contemporary (Path 6 and 5, Figure 1). The literature on the trajectories for the evolution of pathways underlying positive adaptation in adolescents reveals specific interactions between protective factors and risk factors (Cicchetti \& Rogosch, 1996).

\section{Developmental Psychopathology and Dual Diagnosis}

Dual diagnose means that somebody has at least two conditions occurring at the same time and interacting with one other. These are also sometimes called co-occuring disorders or comorbidities. According to Zimberg (1999) a dual diagnosis typology was developed with three subtypes. Type I is a primary psychiatric disorder with substance use only when psychiatrically symptomatic (self-medication). Type II is a primary substance use disorder with substance-induced psychiatric symptoms. Type III is psychiatric and substance use disorders of long duration that are co-occurring or present at different times. Type III is considered the "true" dual disorder state. This typology was found to

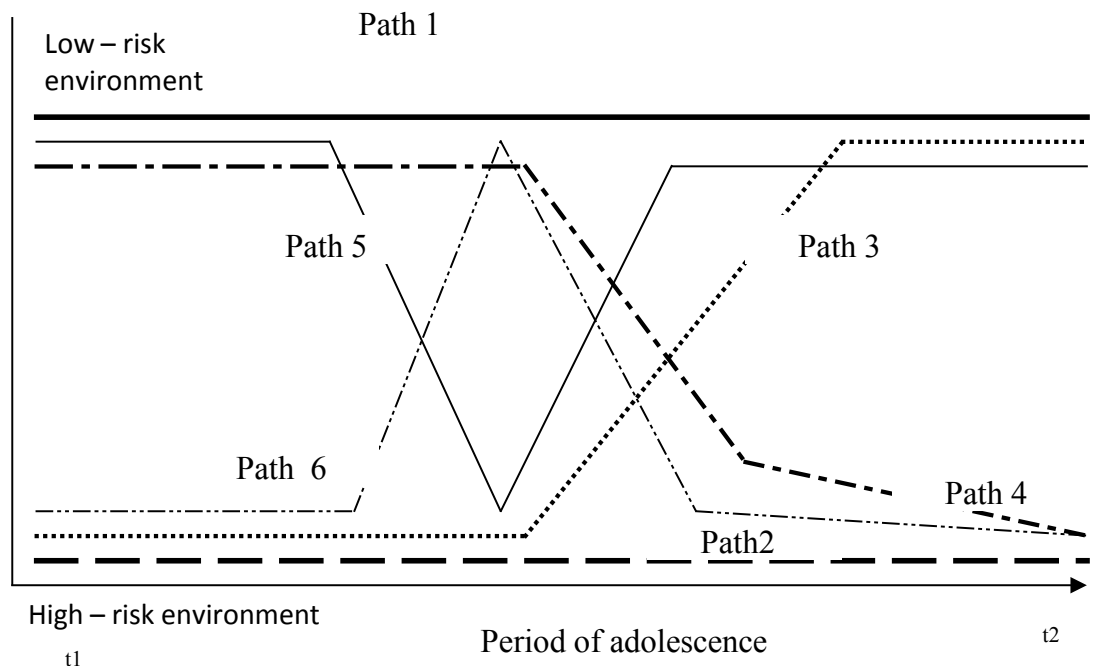

Figure 1. A model of potential developmental paths during adolescence. $\mathrm{t}^{1}$-beginning of adolescence, $\mathrm{t}^{2}$ end of adolescence (source: author's own work based on: Compas et al., 1995). 
be reliable and have consensual validity. It was used with a standardized interview and clinical interview plus questions designed to determine the subtype with patients in psychiatric and substance abuse outpatient programs and with state hospital inpatient dual disorder patients.

Developmental psychopathology as a specific framework can be used in the first two types of Dual Diagnosis. The problems could be connected with the development of disorders and the trajectories of adaptation. From the developmental point of view the second trajectory (according to Zimberg, 1999) involves insights into mental disorders and mental health, non-adaptation and adaptation, and the interactions between them. It enables to see addiction and mental disorders as a complex phenomenon dependent on many mutually related conditions, including vulnerability, biopsychosocial risk factors, and personal engagement (Cierpiałkowska, 2010; Poprawa, 2015). And of course, the question remains whether addiction is a disorder or a symptom of different problems.

\section{Complex - Developmental Model of Addiction}

The most common models to explain the influence of biological, social and psychological factors on the developmental psychopathology model of children and adolescents using and abusing other psychoactive substances were prepared by Luthar, Cicchetti, \& Becker (2000). The models are based on the assumptions that abuse and dependence on psychoactive substances are the result of: 1) dynamically changing in the life cycle interactions between the individual's innate properties and stress events occurring in the environment; 2) the creation of the mechanism of the "vicious circle" at different stages of the child's life; this mechanism basically strengthens the risk factors and weakens the resources, sustaining the processes of preserving maladaptive behaviour patterns; 3) shaping maladaptive patterns of behaviour, consisting of externalization or internalization of mental problems and the disclosure of other health problems. Consideration of comorbidity is critical for forming psychopathology models relevant to etiology, nosology, and intervention in developmental psychopathology approach (Angold, Costello, \& Erkanli, 1999; Bubier, Drabick, \& Breiner, 2009; Costello, Mustillo, Keeler, \& Angold, 2003; Drabick, 2009; Verduin \& Kendall, 2003). The etiological mechanisms responsible for psychological disorders are likely to involve complex interactions among risk and resilience ${ }^{2}$. It means that it is possible to notice some specific mediators (e.g. parents' alcoholism or having a mentor, exposition to violence, poverty) and moderators (sex, age) as predictors of addition or risky behaviours. Additionally, the model points to four groups of risk factors: biological, psychological, social-family and extra-family social factors as well as normative and non-normative stressful events that remain in mutual dynamic relationships in the process of shaping mental and/or health dis${ }^{2}$ The concept of resilience explains the phenomenon of positive adaptation among young individuals exposed to unfavourable life events. The majority of researchers are inclined to consider this concept not as a stable feature of a child, but as a multifactorial, dynamic process of coping with developmental conditions, which leads to positive adaptation (Luthar, Cicchetti, \& Becker, 2000). 
orders and problems in the child. These factors take a significant part in the creation of maladaptive behavioural patterns which involve externalization and internalisation of problems. The research results indicate that the externalization of problems (eg oppositional rebellious behaviour, disorders connected with lack of behaviour control, truancy, socialization disorder) co-exists with addiction appearing in the adolescence period, whereas the internalization of problems (eg anxiety disorders, depressive syndromes, sense of alienation) is connected with addiction manifested in the individual in later periods of life (Chassin, Sher, Hussong, \& Curran, 2013). Important variables that mediate between the family environment and the risk of drinking/taking psychoactive substances by young people include the so-called difficult temperament ${ }^{3}$, cognitive deficits ${ }^{4}$ and expectations about the effects of drinking/taking psychotropic drugs ${ }^{5}$.

The main personality factors involved in the use of psychoactive substances are: 1) neuroticism - negative affective feeling; 2 ) impulsiveness - disinhibition, 3) extraversion - sociability. From the perspective of many empirical studies, the emergence of drinking and using a substance behaviours is connected with high neuroticism, low level of agreeableness and high level of anxiety on the one hand, and high impulsivity, sensation seeking, aggressiveness and psychoticism on the other hand (Sher, 2000).

If psychological problems occur in parents, it is always necessary to distinguish and recognize specific disturbances (effect of parent's illness or problems) and non-specific disturbances, which are the consequences of many other unfavourable factors occurring in the family. These nonspecific aspects are connected with the style of their parental functions, while those specific ones with characteristics that are direct and indirect effects of alcoholism for the family and marital relationship all of them are part of the social-family and extra-family social factors.

\section{Example of solving problems in this field}

Because article has informative and historical perspective example of the studies in this field are presented to show integrative opportunities of this model. Searching for an answer to the question what makes children of alcoholics more prone to develop psychopathological features the following aspects were investi${ }^{3} \mathrm{~A}$ higher level of sociability is a good predictor of reaching for psychoactive drugs by adolescent children of alcoholics as opposed to non-alcoholic children, as Cierpiałkowska (2010) stated.

${ }^{4}$ Some studies confirm the differences between children of alcoholics and non-alcoholics, indicating that the first group is characterized by: a lower level of general intelligence, a reduced level of development of verbal and non-verbal functions manifested in the impairment of spatial perception. Moreover, less developed executive functions co-exist with a rigid and inflexible approach to problem solving and maintaining activity aimed at achieving the goal.

${ }^{5}$ The next group of noticed factors that are important for the emergence of the risk of addiction indicated in the developmental models of psychopathology of children and adolescents are expectations towards the effects of drinking/taking. The expectations evolve in the life cycle - from negative ones related to the unpleasant and antisocial effects of drinking in pre-school and early school years, to positive ones related to the anticipation of tension relief and improvement of cognitive and social functioning during adolescence and early adulthood. Most studies indicate that there are no significant differences between children of alcoholics and non-alcoholics, at various stages of life, in terms of expectations towards psychoactive substances. 
gated: psychological functioning of children and adolescents from families with and without an alcohol problem, their developmental achievement in terms of better or worse adaptation, selected features useful in coping with stress and maintaining mental health. As the starting point the study conducted by Grzegorzewska are described (2013). The author has shown that parents-alcoholics are a very heterogeneous group-they differ significantly in terms of the style of performing parental functions, as well as the degree of differentiation in the activation of specific stressful events resulting from alcoholism, such as the use of aggression, violence or neglect of children ${ }^{6}$. The obtained results confirmed the heterogeneity of the population of children of alcoholics. It turned out that they are a risk group, especially prone to develop mental disorders in terms of the intensity of various symptoms. The risk results from greater psychological susceptibility of children of alcoholics to developmental problems and the specificity of their developmental context. On the other hand, the study confirmed that not all children of alcoholics found it difficult to adapt to social requirements. Some of them (about 40\%) coped well with developmental tasks and despite many negative, often accumulated, traumatic events they could find joy, satisfaction and contentment in life. It remains unclear whether greater risk is a direct result of the impact of alcoholism, or an intermediate product of genetic and environmental influences, including loose family bonds, poor physical and emotional availability of parents, decreased quality of parental functions or the generally nervous and unstable atmosphere of everyday life, filled with conflict (Grzegorzewska \& Farnicka 2013).

As a discussion on presented study it is possible to say that children of alcoholics with the high-level adaptation profile attempted to deal with problems and sought solutions despite difficulties more often. They also sought support and help of the others more frequently. This is consistent with the results of another empirical study in this field, which confirms that adaptive coping styles are those which prefer active problem solving, in contrast to strategies focused on negative emotions, e.g. anger or avoidance. Young people who are oriented at more active coping strategies abuse psychoactive substances less often and/or have more pro-social peers (Wills et al., 2001; Ogińska-Bulik \& Juczyński, 2011). Due to the fact that this impact happens to be stronger, if a teenager experiences intensified life distress, it can be assumed that more active coping strategies buffer the relation between risk and risky behaviors. It is also possible that children with more active coping strategies gather information and consider alternative behaviors more often before taking an action. It is a kind of self-control, which protects a child from his/her will to experiment as a way to cope with difficult situations (Wills et al., 2001). These variables mainly include the impact of peers ${ }^{6}$ Below a short description of the study is presented. The study involved 182 children in two comparison groups (children of alcoholics and children of non-alcoholics) aged 9 - 12. The clinical group consisted of 90 children from families with alcohol problems defined on the basis of a CAST screening test. The control group comprised 92 people from families without alcohol problems. An expression of the resilience of children of alcoholics was the level of a positive adaptation, as measured by two indicators: developmental tasks and life satisfaction. 
and siblings. A significant relationship between the way the older brother was drinking/taking and the level of alcohol/substance use by the younger one has been found. Additionally, the following cultural and social factors should be mentioned: access to substances, social values and social expectation towards the way of development (ESPAD, 2015; Report of European Monitoring Centre for Drugs and Drug Addiction, 2016; 2017; 2018).

\section{Conclusion}

Thus, it should be summarised that developmental psychopathology pays special attention to comparing maladaptive forms of behaviour to a developmental norm, which is defined in two ways: either in terms of developmental tasks which a child in a specific stage of life should manage or realize, or in terms of universality (frequency) or rarity of certain behaviour or manner of emotional experience at a specific age (quantitative norm) (Cicchetti \& Rogosch, 1996; Kazdin \& Kagan, 1994). Developmental changes could be observed as positive and negative outputs of development (health or disorders). They could be described both in categorical and dimensional models. The process of development is recognized in the dimensional model but the effect of this process is seen in the categorical model (diagnostic categories represent discrete syndromes ${ }^{7}$, Beauchaine, 2003; Drabick, 2009). This assumes that normative developmental tasks could be treated as predictors of the next step of development. The symptoms of psychopathology can be the results of coping with developmental tasks. In the case of addictions, many symptoms need to be treated dimensionally (Krueger \& Markon, 2011). According to the literature, addictions are increasingly treated not only as qualitatively different categories (a person either is or is not addicted), but also as gradual, quantifiable increases in harmful symptoms of addictive behaviours (Krueger, Markon, Patrick, Benning, \& Kramer, 2007). A less categorical and more dimensional approach to addiction is evident in the latest DSM 5 (2016) classification. From this perspective, early detection of disturbing behavioural and emotional signals increases the chances of preventing adverse developmental outcomes and preventing the development of substance addictions in the future. Preventive measures should be aimed at relatively young children before the full symptoms of dependency on selected behaviours emerge. They can be targeted and taken into account in prevention programmes.

By applying the perspective of developmental psychopathology, we can better understand the specific issues associated with the complex system of conditioned dependencies in which biological, psychological and social factors are in constant interaction. Recognition of the differentiation of developmental pathways that lead to healthy or pathological pathways allows us to explain the complexity

${ }^{7} D S M$ uses a categorical model for conceptualizing diagnoses, but many symptoms cause clinically significant impairment at subthreshold levels reinforcing the importance of evaluating psychological symptoms using both categorical and dimensional approaches. A dimensional approach could facilitate identification of children who are at risk for more severe or pernicious courses prior to the full presentation of symptoms. 
of the mechanisms responsible for initiating and sustaining addictive behaviors. It could be a good approach to early recognition of the symptoms of addictions. It also enables the development of effective prevention and treatment programmes.

\section{Conflicts of Interest}

The authors declare no conflicts of interest regarding the publication of this paper.

\section{References}

Angold, A., Costello, E. J., \& Erkanli, A. (1999). Comorbidity. Journal of Child Psychology and Psychiatry, 40, 57-87. https://doi.org/10.1111/1469-7610.00424

Beauchaine, T. P. (2003). Taxometrics and Developmental Psychopathology. Development and Psychopathology, 15, 501-527. https://doi.org/10.1017/S0954579403000270

Blaszczynski, A., \& Nower, L. (2002). A Pathways Model of Problem and Pathological Gambling. Addiction, 97, 487-499. https://doi.org/10.1046/j.1360-0443.2002.00015.x

Bubier, J., Drabick, D. A., \& Breiner, T. (2009). Autonomic Functioning Moderates the Relation between Contextual Factors and Externalizing Behaviors among Inner-City Children. Journal of Family Psychology, 23, 500-510. https://doi.org/10.1037/a0015555

Chassin, L., Sher, K., Hussong, A., \& Curran, P. (2013). The Developmental Psychopathology of Alcohol Use and Alcohol Disorders: Research Achievements and Future Directions. Development and Psychopathology, 25, 1567-1584. https://doi.org/10.1017/S0954579413000771

Cicchetti, D. (1993). Developmental Psychopathology: Reactions, Reflections, Projections. Developmental Review, 13, 471-502. https://doi.org/10.1006/drev.1993.1021

Cicchetti, D. (2013). An Overview of Developmental Psychopathology. In P. Zelazo (Ed.), The Oxford Handbook of Developmental Psychology (pp. 455-480). New York: Oxford University Press.

Cicchetti, D., \& Rogosch, F. A. (1996). Equifinality and Multifinality in Developmental Psychopathology. Development and Psychopathology, 8, 597-600. https://doi.org/10.1017/S0954579400007318

Cierpiałkowska, L. (2010). Funkcjonowanie dzieci alkoholików psychospołeczne źródła deficytów i zasobów. In L. Cierpiałkowska, \& M. Ziarko (Eds.), Psychology of Addiction Alcoholism (pp. 253-289). Warszawa: WAiP.

Cierpiałkowska, L., \& Grzegorzewska, I. (2016). Children of Alcoholics in Developmental and Clinical Perspective. Poznań: UAM Press.

Compas, B. E., Hinden, B. R., \& Gerhardt, C. A. (1995). Adolescent Development: Pathways and Processes of Risk and Resilience. Annual Review of Psychology, 46, 265-293. https://doi.org/10.1146/annurev.ps.46.020195.001405

Conrod, P. J., O’Leary-Barrett, M., Newton, N., Topper, L., Castellanos-Ryan, N., Mackie, C., \& Girard A. (2013). Effectiveness of a Selective, Personality-Targeted Prevention Program for Adolescent Alcohol Use and Misuse: A Cluster Randomized Controlled Trial. JAMA Psychiatry, 70, 334-342. https://doi.org/10.1001/jamapsychiatry.2013.651

Costello, E. J., Mustillo, S., Erkanli, A., Keeler, G., \& Angold, A. (2003). Prevalence and Development of Psychiatric Disorders in Childhood and Adolescence. Archives of General Psychiatry, 60, 837-844. https://doi.org/10.1001/archpsyc.60.8.837 
Davies, T., \& Cranston, P. (2008). Youth Work and Social Networking: Final Research Report. Leicester: National Youth Agency.

Drabick, D. A. (2009). Depression Comorbidity among Children: Potential Explanations, Shared Risk Factors, and Directions for Future Research. In B. T. Naylor (Ed.), Depression in Children (pp. 1-23). Huntington, NY: Nova Science.

ESPAD (2015). The European School Survey Project on Alcohol and Other Drugs European Monitoring Centre for Drugs and Drug Addiction Report. http://www.espad.org/report/home

Gentile, D. A., Anderson, C. A., Yukawa, S., Ihori, N., \& Saleem, M. (2009). The Effects of Prosocial Video Games on Prosocial Behaviors: International Evidence from Correlational, Longitudinal, and Experimental Studies. Personality and Social Psychology Bulletin, 35, 752-763. https://doi.org/10.1177/0146167209333045

Gentile, D. A., Choo, H., Liau, A., \& Khoo, A. (2011). Pathological Video Game Use among Youths: A Two-Year Longitudinal Study. Pediatrics, 127, 319-329. https://doi.org/10.1542/peds.2010-1353

Griffiths, M. D. (2003). Adolescent Gambling: Risk Factors and Implications for Prevention, Intervention, and Treatment. Reducing Adolescent Risk: Toward an Integrated Approach. In D. Romer (Ed.), Reducing Adolescent Risk: Toward an Integrated Approach (pp. 223-238). Thousand Oaks, Calif., London: Sage Publications. https://doi.org/10.4135/9781452233611.n25

Grzegorzewska, I. (2013). Resilience of Children of Alcoholics. Warsaw: Scholar.

Grzegorzewska, I., \& Cierpiałkowska, L. (2017). Behavioral Addiction. Warsaw: PWN.

Grzegorzewska, I., \& Farnicka, M. (2013). The Correlates of the Resilience of the Children of Alcoholics. Psychology, 4, 956-960. https://doi.org/10.4236/psych.2013.412138

Haass-Koffler, C. L., \& Bartlett, S. E. (2012). Stress and Addiction: Contribution of the Corticotropin Releasing Factor (CRF) System in Neuroplasticity. Frontiers in Molecular Neuroscience, 5, 91. https://doi.org/10.3389/fnmol.2012.00091

Hawkins, J. D., \& Fitzgibbon, J. J. (1993). Risk Factors and Risk Behaviors in Prevention of Adolescent Substance Abuse. Adolescent Medicine, 4, 249-262.

Hu, Y., Fang, Z., Yang, Y., Rohlsen-Neal, D., Cheng, F., \& Wang, J. (2018). Analyzing the Genes Related to Nicotine Addiction or Schizophrenia via a Pathway and Network Based Approach. Scientific Reports, 8, 2894. https://doi.org/10.1038/s41598-018-21297-x

Israelashvili, M., Kim, T., \& Bukobza, G. (2012). Adolescents' Over-Use of the Cyber World-Internet Addiction or Identity Exploration? Journal of Adolescence, 35, 417-424. https://doi.org/10.1016/j.adolescence.2011.07.015

Kazdin, A., \& Kagan, J. (1994). Models of Dysfunction in Developmental Psychopathology. Clinical Psychology: Science and Practice, 1, 35-52. https://doi.org/10.1111/j.1468-2850.1994.tb00005.x

Krueger, R. F., \& Markon, K. E. (2011). A Dimensional-Spectrum Model of Psychopathology: Progress and Opportunities. Archives of General Psychiatry, 68, 10-11. https://doi.org/10.1001/archgenpsychiatry.2010.188

Krueger, R. F., Markon, K. E., Patrick, C. J., Benning, S. D., \& Kramer, M. D. (2007). Linking Antisocial Behavior, Substance Use, and Personality: An Integrative Quantitative Model of the Adult Externalizing Spectrum. Journal of Abnormal Psychology, 116, 645-666. https://doi.org/10.1037/0021-843X.116.4.645

Luthar, S. S., Cicchetti, D., \& Becker, B. (2000). The Construct of Resilience: A Critical Evaluation and Guidelines for Future Work. Child Development, 71, 543-562. 
https://doi.org/10.1111/1467-8624.00164

Moffitt, T. E., Arseneault, L., Belsky, D., Dickson, N., Hancox, R. J., Harrington, H. et al. (2011). A Gradient of Childhood Self-Control Predicts Health, Wealth, and Public Safety. Proceedings of the National Academy of Sciences, 108, 2693-2698. https://doi.org/10.1073/pnas.1010076108

Niemz, K., Griffiths, M., \& Banyard, P. (2005). Prevalence of Pathological Internet Use among University Students and Correlations with Self-Esteem, the General Health Questionnaire (GHQ), and Disinhibition. Cyber Psychology \& Behavior, 8, 562-570. https://doi.org/10.1089/cpb.2005.8.562

Ogińska-Bulik, N., \& Juczyński, Z. (2011). Resiliency in Children and Adolescents: Characteristic and Measurement-Polish Scale SPP-18. Polish Psychological Forum, 16, 7-28.

Petry, N. (2015). Behavioral Addictions. Oxford: Oxford Press. https://doi.org/10.1093/med/9780199391547.001.0001

Poprawa, R. (2015). Doomed to Problems. In Search of Personality Conditions of Drinking Problem in Men. Warsaw: Wydawnictwo Scholar.

Report of European Monitoring Centre for Drugs and Drug Addiction (2016). European Drug Report 2016. Luxembourg: Publications Office of the European Union.

Report of European Monitoring Centre for Drugs and Drug Addiction (2017). European Drug Report 2017: Trends and Developments. Luxembourg: Publications Office of the European Union.

Report of European Monitoring Centre for Drugs and Drug Addiction (2018). European Drug Report 2018: Trends and Developments. Luxembourg: Publications Office of the European Union.

Rutter, M., Dunn, J., Plomin, R., Simonoff, E., Pickles, A., Maughan, B. et al. (1997). Integrating Nature and Nurture: Implications of Person-Environment Correlations and Interactions for Developmental Psychopathology. Development and Psychopathology, 9, 335-364. https://doi.org/10.1017/S0954579497002083

Ryan, R. M., Rigby, C. S., \& Przybylski, A. (2006). The Motivational Pull of Video Games: A Self-Determination Theory Approach. Motivation and Emotion, 30, 347-364. https://doi.org/10.1007/s11031-006-9051-8

Sher, K. (2000). The Psicological Characteristic of Children of Alcohloics. Alkohol a Zdrowie, 26, 164-183.

Tapert, S. F., Caldwell, L., \& Burke, C. (2005). Alcohol and the Adolescent Brain: Human Studies. Alcohol Research \& Health, 28, 205-212.

Tomkins, D. M., \& Sellers, E. M. (2001). Addiction and the Brain: The Role of Neurotransmitters in the Cause and Treatment of Drug Dependence. CMAJ: Canadian Medical Association Journal, 164, 817-821.

Verduin, T., \& Kendall, P. C. (2003). Differential Occurrence of Comorbidity within Childhood Anxiety Disorders. Journal of Clinical Child and Adolescent Psychology, 32, 290-295. https://doi.org/10.1207/S15374424JCCP3202_15

Wills, T. A., Sandy, J. M., Yaeger, A. M., Cleary, S. D., \& Shinar, O. (2001). Coping Dimensions, Life Stress, and Adolescent Substance Use: A Latent Growth Analysis. Journal of Abnormal Psychology, 110, 309-323. https://doi.org/10.1037/0021-843X.110.2.309

Zimberg, S. (1999). A Dual Diagnosis Typology to Improve Diagnosis and Treatment of Dual Disorder Patients. Journal of Psychoactive Drugs, 31, 47-51.

https://doi.org/10.1080/02791072.1999.10471725 